\title{
User Ratings and Willingness to Express Opinions Online
}

\author{
Jaehyun Hong \\ Minneapolis, Minnesota, USA \\ E-mail: jaehyunhong@gmail.com
}

Hee Sun Park (Corresponding author)

Department of Communication, Michigan State University

East Lansing, MI 48824-1212, USA

Tel: 1-517-355-3480Ｅ-mail: heesun@msu.edu

Received: January 5, 2010 Accepted: January 24, 2010 doi:10.5539/ijms.v3n2p2

\begin{abstract}
The current study examined the effects of volume and valence of user ratings in a movie rating Web site on individuals' perception about the user ratings and also on individuals' willingness to express their opinions online. In study 1 , undergraduate participants were randomly assigned to one of 2 (volume: low and high) $\times 2$ (valence: positive and negative) conditions. In study 2, undergraduate participants were randomly assigned to one of 4 (volume: low, high, super high, and mega high) $\times 2$ (valence: positive and negative) conditions. The findings showed that individuals perceived others to be more affected by user ratings than themselves, that the perceived effect of user ratings on others was positively related to individuals' willingness to express opinions, and that the extent to which individuals' own rating differed from the valence of user ratings was positively related to willingness to express opinions in the negative valence condition, but negatively related to willingness to express opinions in the positive valence condition. This study applied social science theories to better understand the mechanism of individuals' opinion expression online. By manipulating user ratings about unreleased movies, this study controlled potential effects of participants' familiarity with rated movies.
\end{abstract}

Keywords: User ratings of movies, Opinion polls, Internet, Third person effect

\section{Introduction}

People often seek out others' opinions and experiences as information before making decisions to purchase products or services. Word of mouth (WOM) represents an aspect of such information exchange among consumers (Anderson, 1998; Arndt, 1967; Ozcan, 2004). WOM occurs in interpersonal settings (e.g. face-to-face) and increasingly on the Internet. One of the many functions of the Internet is to provide handier access to WOM and easier participation in WOM for movies; many Internet sites provide a place where users can post their ratings and comments about movies and become part of WOM. Online WOM is of interest to both scholars and marketing practitioners regarding why and how people participate in WOM.

Online WOM has several interesting features. First, WOM on the Internet typically or often comes from anonymous others, not from one's own social networks and interpersonal relationships. Second, WOM on the Internet often provides information on the number of others who like or dislike certain movies, and those numbers tend to be much larger than those available for off-line WOM (i.e. the number of people in one's social networks). Third, users can see the results of ongoing polls about certain movies on a daily basis, if they choose to do so. Fourth, participation in WOM on the Internet is completely voluntary and may reflect the interactive aspects of individuals' expressing their opinions affecting and being affected by public opinions. That is, individuals' willingness to express their opinions can be affected by the existing public opinions on the Internet site, and, at the same time, individuals may also want to affect public opinion by expressing their opinions.

The current study focuses on the relationship between individuals' perceptions of public opinions and their willingness to express their own opinions to be a part of online WOM. User ratings on the Internet have both aspects of WOM and public opinion polls on the Internet. The purpose of this paper is to explore the mechanism of user ratings of movies by focusing on their role as public opinion polls. People have a tendency to 
overestimate media effects on others and underestimate media effects on themselves (Davison, 1983). Similarly, individuals may perceive that others, compared to themselves, are more influenced by user ratings and that this discrepancy may motivate individuals to express their opinions. Based on the Third-Person Effect (TPE), this paper advances hypotheses concerning the mechanism of opinion expression as a part of WOM on the Internet.

\subsection{User Ratings}

WOM on the Internet takes various forms, ranging from users' specific comments to simple numeric evaluations. User ratings are similar to public opinion polls in that they show the volume and valence of public opinion about movies with numerical values at a glance. Volume, which refers to the total quantity of interaction, can have an informative effect on awareness, while valence, which is defined as the quality of WOM concerning positive or negative evaluation of movies, can have a persuasive effect on audience's attitudes toward movies (Liu, 2006). Previous research on WOM on the Internet concerning movies has focused on the volume and valence of WOM and the predictive effects on box office revenue (Dellarocas, Awad, \& Zhang, 2004; Liu, 2006). The volume of user ratings is often the most significant factor for predicting future box office revenue (Dellarocas et al., 2004; Duan, Gu and Whinston, 2005; Liu, 2006). The persuasive role of valence of WOM, however, has not been evidenced in previous studies; the valence of WOM concerning a certain movie was not related to the ticket sales at the box office for that movie (Dellarocas et al., 2004; Duan et al., 2005; Liu, 2006).

A couple of explanations may exist for why the valence of user ratings did not have much impact on attitudes and behaviors concerning movies. First, the previous studies considered the valence of WOM as an absolute value: a positive (e.g. a high rating) or negative value (e.g. a low rating). Then, the researchers assumed a simple relationship between the valence of WOM and people's movie selections, with positive WOM increasing an audience's positive attitude and negative WOM reducing it. The effect of valence of WOM, however, may not simply come from the valence of WOM on the Internet but may result from a discrepancy between the valence of WOM and one's perceptions about movies. Thus, it could be helpful in clarifying the effects of valence if the valence of WOM is also examined as the discrepancy between others' user ratings and an individual's own ratings.

Second, people's immediate responses to user ratings of a movie were not considered in those previous studies. WOM on the Internet, especially numeric ratings of users or movie watchers, is similar to opinion polls on the Internet and people's responses can be disclosed immediately right in the WOM itself. Hence, by examining the characteristics of public opinion polls on the Internet, it may be possible to better understand how and why individuals respond or do not respond to the WOM on the Internet and whether or not individuals are influenced by WOM on the Internet.

\subsection{User Ratings as Public Opinion Polls}

WOM on the Internet, especially through user ratings, takes on some characteristics of public opinion polls on the Internet. First, WOM on the Internet comes from a diverse group of people. Various Internet sites provide places for individuals to directly access thousands of anonymous others' opinions and post their own opinions. Dellarocas et al. (2004) claims that WOM has more persuasive power when it comes from different social groups rather than one's own group. Especially, user ratings, which consist of numerical evaluations, are a type of opinion poll about certain movies in that they show at once how many people like or dislike the movie.

The second characteristic of user ratings on the Internet as online public opinion polls is interactivity. Interactivity is characterized as the activity of communication exchange (Rafaeli, 1988; Schultz, 1999). The Internet is a public area where public opinion is shaped through opportunities for each individual to express his or her own opinion and to participate in debates and polls (Savigny, 2002). While in traditional media the public has become a passive audience who just reacts or responds to media content (Franklin, 1994), on the Internet people are positioning themselves as the participants rather than only the audience. Online discussion boards, chat rooms, and public opinion polls are examples of interactive communication among users (Schultz, 2000).

Online opinion polls are neither scientific nor representative because of the type of sampling (e.g., self-selected participants). It is possible for multiple voters to manipulate rating results (Kent, Harrison and Taylor, 2006). It has been argued that the main role of online opinion polls may not be to measure the public opinion climate but to allow people to express their opinions (Kent et al., 2006). Although online opinion polls may not provide accurate public opinion, individuals may still use the results of online polls to estimate public opinion (Wu and Weaver, 1997).

People might be more motivated to join online discussions or opinion polls because of these non-scientific aspects of online opinion polls. The openness to everyone and the self-selected voluntary participation nature of 
polls on the Internet may motivate people to react to the results of ongoing opinion polls, which people can see before they participate. One possible explanation is that people participate in the polls not only to express their own opinions but also to influence the opinion poll results. The decision to participate in ongoing polls may be influenced by people's concerns for others who may be more vulnerable to the effects of poll results than themselves. Especially when the poll results disagree with their opinions and when they perceive that others may be more influenced by these poll results, people may be more willing to participate in the polls.

\subsection{Public Opinion Perception and the Third-Person Effect}

The TPE is based on individuals' misperceptions of the effect of media messages on themselves and others. An individual who is exposed to media messages suspects that others will be more heavily influenced by the messages than they really are. Specifically, the media has less influence on "me" or "you," than it has on "them" - the third person (Davison, 1983). Research has shown that the TPE is stronger for controversial news reports (Salwen and Driscoll, 1997); undesirable messages, such as pornography (Gunther, 1995); and persuasive media messages, such as commercials (Shah, Faber and Youn, 1999). Public opinion polls in news coverage can also lead to a biased judgment of the assumed influence of opinion polls on others (Gunther and Storey, 2003). Perloff (1999) indicated that the TPE is composed of perceptual and behavioral components. The perceptual component refers to the discrepancy between self and others, which can lead to the misperception of media effects on others. The behavioral component of the TPE is the first-persons' reactions to their incorrectly-anticipated media impact on the third-person. Focusing on the perceptional component of TPE first, it is hypothesized that people are more likely to minimize the effect of user ratings on themselves and to maximize the effect of user ratings on others.

\section{H1: User ratings on the Internet are perceived by individuals to have a greater effect on others than on themselves.}

The volume of user ratings can affect the perceptual gap between self and others. In traditional opinion polls, people express their opinions without consideration of other's opinions, while in online opinion polls, people can see the results of the ongoing polls before they participate. Mere exposure to the poll results has an impact on people's attitude changes (Morwitz and Pluzinski, 1996) and people's estimation of the effects of opinion polls on others (Gunther and Storey, 2003). Higher volumes of user ratings may be perceived to be better representations of public opinion at large and to be more persuasive for others. Thus, the following hypothesis is advanced.

H2: The extent to which the perceived effects of user ratings are greater on others than on self is larger in a high volume condition than in a low volume condition of user ratings.

\subsection{TPE and Willingness to Express Opinions}

One important aspect of online polling is self-selected participation. Traditional public opinion polls have used survey methods, such as telephone surveys, interviews, and visiting houses. Although the decision to answer the survey questions fully depends on people's own intentions, the chance to participate in traditional opinion polls is determined by a sampling method chosen by the surveyors or polling agencies. For opinion polls on the Internet, however, the decision to participate in the polls is up to individuals' volition to express their opinion publicly. Thus, motivations and behavioral patterns reflected in participation in Internet opinion polls may be different from those for participation in traditional opinion polls.

The public opinion formation process arises not only from interaction among individuals but also from their perceptions of the opinion climate. Individuals observe the overall distribution of others' opinions through quasi-statistical pictures drawn from various social circumstances and assess which opinion is dominant (Noelle-Neuman, 1974). The Spiral of Silence theory assumes that fear of isolation motivates people to keep their opinions to themselves, rather than speaking out with their opinions publicly, if they perceive their views to be among the minority (Noelle-Neuman, 1974). On the Internet, however, fear of isolation may not be a factor for affecting individuals' willingness to express opinions. One of the main features of the Internet is the anonymity which hides identity. People may be less concerned with what others may think of them but more concerned about how others would be affected by the online opinion poll results when deciding whether or not to express their opinions online.

In the cyber-world people may voluntarily participate in online polls due to their concern for the perceived effect of online poll results on others. According to TPE, people's motivations for their actions could stem from their misperceived effect of mass media on others (Davison, 1983). In relation to behavioral component of TPE (Perloff, 1999), individuals' willingness to express their opinions on the Internet may be an indication of their 
reactions to misperceived impact of user ratings on the third-person. Becoming participants in WOM can be influenced by altruism, a desire to warn others (Dichter, 1966), and by consumer satisfaction level (Anderson, 1998). Concern for others can be a reason for individuals' willingness to engage in WOM on the Internet. The more people believe that the results of ongoing online polls have a great impact on others, the more willing they will be to participate in the polls. Thus, the following hypothesis is offered.

H3: As individuals perceive greater effects of user ratings on others, their willingness to express opinions is more likely to increase.

In addition to the positive and negative valence distinctions of user ratings, the current study conceptualizes the valence of user ratings as the discrepancy between an average user rating and an individual's own ratings. If the results of the user ratings are in opposition to people's own evaluations (if there is a big difference between the user ratings and one's rating), it could be perceived as undesirable and people may be more likely to underestimate the effect of user ratings on themselves and to overestimate the effect on others. Thus, as the valence discrepancy between the user ratings and one's own rating becomes larger, individuals may experience greater willingness to express their opinions due to their greater concern for others being influenced by the user ratings and in an effort to minimize the effects of user ratings on others. In short, when user ratings and people's opinions are more likely to be different, people may have stronger willingness to express their opinions.

H4: As the discrepancy between the valence of user ratings and individuals' self ratings increases, their willingness to express opinions is more likely to increase.

\section{Study 1 Method}

\subsection{Participants}

Undergraduates in Communication and Advertising classes at Michigan State University in the United States participated in the study in exchange for extra credit for each class. In total, 403 students voluntarily participated in the survey. Of the participants, nine were Korean students who might have had the greatest possibility of having been previously influenced by information about the stimulus materials (Korean movies) from Korean Websites or other sources. Thus, the responses from those Korean students were removed from the data. The responses of 394 participants (age $M=20.18, S D=1.40 ; 64.7 \%$ women) were used in the final analysis. The ethnic make-up of the participants were $85.3 \%$ Whites/Caucasian, 1.6\% Hispanic/Latino, 7.8\% Blacks/African Americans, 0.3\% Native Hawaiian/Other Pacific Islander, 0.3\% American Indian/Alaska Natives, 3.1\% Asians, $0.5 \%$ other races, and $1.3 \%$ mixed (i.e. two or more races). To provide comparisons of the current sample with the U.S. population, census data are reported here. According to the U.S. Census Bureau (2000a, 2000b), 51\% of the U.S. population is women and $6.7 \%$ belongs to an age group of 20 to 24 years. The U.S. population consists of 75.1\% Whites/Caucasians, 12.3\% Blacks/African Americans, 0.9\% American Indian/Alaska Natives, 3.6\% Asians, $0.1 \%$ Native Hawaiian/Other Pacific Islander, 5.5\% Some other races, and 2.4\% two or more races. Additionally, of the U.S. population, $12.5 \%$ were considered as Hispanic/Latino and $87.5 \%$ were not Hispanic/Latino (The U.S. Census Bureau, 2000c).

\subsection{Design and Procedure}

The current study used a 2 (volume: high and low) $\times 2$ (valence: positive and negative) between-subject design. The volume of user ratings was manipulated as the number of hypothetical students who were said to have participated in the rating. In the high volume conditions, the ratings of 350 students were provided, while, in the low volume conditions, the ratings of 15 students were provided to participants. We decided on these numbers of student ratings for the low and high volume conditions to lead the participants to perceive them to be realistic, considering the total number of undergraduates majoring in Communication and Advertising in this university. Because movie ratings often use "stars" in the print or online media reviews (e.g. a three-star movie, a four-star movie), the valence of user ratings was manipulated as the number of stars that were color-filled. In the positive valence condition, four of five stars were yellow-colored and one had no color filled, while, in the negative valence condition, one of five stars was yellow-colored and four had no color filled. The five stars and the number of ratings were placed next to each movie poster and above a movie synopsis. The study was conducted on the Internet in order to provide similar circumstances to the real situation of online ratings for participants. Research participants were randomly assigned to one of the four conditions. After answering questions about their demographic information, participants were shown a movie poster and synopsis with no user ratings provided first and asked to indicate their own ratings. Then, a simple script was presented to participants to make participants believe that the user ratings they were about to see were really other students' ratings. The script said that "The Department of Communication at Michigan State University is collecting students" opinions about foreign movies in order to host an International Film Festival next year. The user rating about a movie was 
produced by ratings of other students in the last semester and participants' rating in this survey also will be included in this rating for other students for next semester." Participants were shown the user ratings placed next to the movie poster and synopsis and asked to respond to the items measuring perceived effects of user ratings and willingness to express their opinions.

\subsection{Stimulus}

In order to control the effect of information from other sources, it was decided to use movies unknown to American participants. The current study used hypothetical students' ratings of three Korean movies, which were released between January and August, 2007, and ranked high in the Box Office in Korea, but were not released in the U.S. In addition, to avoid the confounding effect of genre preference, the three movies were selected from different genres: drama, comedy, and horror. The three movies were Secret Sunshine (drama), 200 Pounds Beauty (comedy), and Black House (horror). The participants were randomly assigned to one of three movie conditions (30.5\% in Secret Sunshine condition; 37.3\% in 200 Pounds Beauty condition, and 32.3\% in Black House condition. The English version of the posters and a simple synopsis of each movie were presented as information about the movies to participants. When examined for potential effects of the motive types (e.g. either as a fixed or random factor in ANOVA), the analyses showed no significant nor substantial effects on any of the variables in the study. Thus, such analyses are not reported.

\subsection{Measures}

All the measures used a 6-point scale from "0-not at all" to "5-very much." Table 1 shows means and standard deviations in each experimental condition. Table 2 shows questionnaire items for each variable.

\subsubsection{Valence Discrepancy}

In addition to the valence of manipulated user rating as positive valence (i.e. four yellow-colored stars out of five stars) and negative valence (i.e. one yellow-colored star out of five stars), valence discrepancy was assessed as the absolute difference between the user ratings and participant's self ratings before exposure to user ratings (e.g., when a participant's self-rating score before exposure to user ratings was 4 , his or her valence discrepancy score would be 3 if he or she was in the negative valence condition). Participants were asked to indicate their ratings of a movie before being exposed to the manipulated user ratings. Each person's rating of the movie was measured with six items (interesting, boring [recoded], appealing, impressive, exciting, and like a waste of time [recoded]) and one additional item ("If you were to rate this movie, your rating of this movie would be out of $5 ")(\alpha$ $=.92$ ) and an average score across the seven items was used as each participant's self rating score.

\subsubsection{The third-person Effect of User Ratings}

The third-person effect (TPE) was measured as perceived effects of user ratings on self and on other students. After being exposed to the manipulated user ratings, participants answered three items $(\alpha=.91)$ measuring the perceived effect of user ratings on self (e.g., "how much do you think this rating has affected your ratings of the movie?") and three items $(\alpha=.94)$ measuring the perceived effect of user ratings on other students (e.g., "how much do you think this rating has affected other students' attitudes toward the movie?"). The three items were identical except for the first person (you) and third-person (other students) designations (e.g., "how much do you think this rating has affected your / other students' expectations of the movie?"). Perceived effect of user ratings on self and perceived effect of user ratings on others were correlated, $r(380)=.62, p<.001$.

\subsubsection{Willingness to Express One's Opinion}

Willingness to express their opinions was measured with four items $(\alpha=.74)$ (e.g., "I am willing to post my rating on a Web site for this movie," and "If you were to see information about this movie on other Web site, how much would you wish to participate in a user rating of this movie?").

\section{Study 1 Results}

It was predicted that individuals would perceive user ratings to have greater effect on others than on self (H1), especially if user ratings indicated a high volume rather than a low volume (H2). Perceived effect of user ratings on others (H3) and valence discrepancy (H4) were predicted to be positively related to willingness to express opinions. Valence was included in mixed ANOVA analyses testing hypotheses 1 and 2. Valence and valence discrepancy were included as predictors in multiple regression analyses testing hypotheses 3 and 4.

\subsection{Perceived Effects of User Ratings on Self and Others}

\subsubsection{Target (H1)}

Hypothesis 1 predicted that the effect of user ratings would be larger on others than on self. A 2 (volume: high 
versus low) $\times 2$ (valence: positive versus negative) $\times 2$ (target: self versus other) mixed ANOVA with target as a within-subject factor was conducted to compare the perceived effect of user ratings on target (self and other). The analysis revealed a significant main effect for target, $F(1,388)=156.19, p<.001, \eta^{2}=.07$. Consistent with $\mathrm{H} 1$, the perceived effect of user ratings on others $(M=2.68, S D=1.25)$ was significantly higher than on self ( $M$ $=1.97, S D=1.36$ ).

\subsubsection{Volume (H2) and Valence}

$\mathrm{H} 2$ predicted that the differential effects of user ratings on self and others would be greater in high volume than low volume conditions. The analysis did not reveal significant main effects for volume, $F(1,388)=0.78, p$ $=.38, \eta^{2}=.00$, or valence, $F(1,388)=2.20, p=.14, \eta^{2}=.004$. The two-way interaction between volume and target was not significant, $F(1,388)=2.13, p=.15, \eta^{2}=.001$. The two-way interaction between valence and target was not significant, $F(1,388)=3.08, p=.08, \eta^{2}=.001$. The three-way interaction among volume, valence, and target was not significant, $F(1,388)=0.02, p=.89, \eta^{2}=.00$. Thus, inconsistent with $\mathrm{H} 2$, individuals' perceived effects of user ratings on self versus others were not affected by volume. Additionally, individuals' perceived effects of user ratings on self and others were not affected by positive and negative valence of user ratings.

\subsection{Willingness to Express One's Opinion}

Perceived effects of user ratings on others (H3) and the valence discrepancy between the user ratings and individuals' self ratings (H4) were hypothesized to predict individuals' willingness to express their opinion. In addition to the hypothesized predictors (valence discrepancy, perceived effect of user ratings on self, and perceived effect of user ratings on others), volume and valence were also included in the multiple regression as predictors for willingness to express opinion. Before conducting the analysis, the two volume conditions were coded with low volume as 0 and high volume as 1 to create a dummy variable. The two valence conditions were coded with negative valence as 0 and positive valence as 1 to create another dummy variable. Continuous predictor variables were mean-centered. Mean-centered variables were used as the first-order predictors and for creating the second-order product terms. Hierarchical multiple regression analysis was conducted with the mean-centered continuous variables and the dummy variables in the first block and the second-order product terms of the predictor variables in the second block. No other higher-order nor nonlinear relationships were observed. An examination of residuals and various indexes showed no violation of statistical assumptions.

The overall model was significant, $F(15,370)=4.03, p<.001$, adj. $R^{2}=.11$. As shown in Table 3, the predictors in the first block and the second block contributed significantly to variances in willingness to express opinions. Among the first-order predictors, consistent with H3, perceived effect on others was significantly positive, indicating that as individuals perceived greater effects of user ratings on others, they were more willing to express their opinions. The main effect of perceived effect on others was further qualified by the significant interaction term of perceived effect on self by perceived effect on others. Although the data were inconsistent with $\mathrm{H} 4$ in that valence discrepancy was not a significant predictor of willingness to express opinion, the interaction term of valence by valence discrepancy was significant, indicating that the relationship between valence discrepancy and willingness to express opinions was moderated by valence.

Simple regression analyses probing the interaction between valence and valence discrepancy indicated that valence discrepancy was a positive predictor of willingness to express opinions in the negative valence condition, unstandardized coefficient $(B)=0.21, S E=0.07, \beta=.22, t=3.07, p=.002$. That is, when the user ratings indicated 1 point out of 5 possible points (i.e. only 1 star out of 5 stars were yellow-colored), as the discrepancy between individuals' self ratings and the user ratings was greater, the more individuals were willing to express their opinions. In the positive valence condition, however, valence discrepancy was a negative predictor of willingness to express opinions, $B=-0.29, S E=0.09, \beta=-.23, t=-3.12, p=.002$. That is, when the user ratings indicated 4 points out of 5 possible points (i.e., 4 stars out of 5 stars were yellow-colored), as the discrepancy that existed between individuals' self ratings and the user ratings was greater, the less individuals were willing to express their opinions.

For the interaction between perceived effect on self and perceived effect on others, simple regression analyses were conducted at various points of perceived effect on self. When perceived effect on self was at 1 SD below its mean, there was a positive relationship between perceived effect on others and willingness to express opinions, simple slope $b=0.11, S E=0.09, t=1.15, p=.25$. The positive relationship between perceived effect on others and willingness to express opinions became stronger as perceived effect on self became stronger, simple slope $b$ $=0.21, S E=0.11, t=1.92, p=.06$, when perceived effect on self was at $2 \mathrm{SD}$ below its mean. On the other hand, when perceived effect on self was at $1 \mathrm{SD}$ above its mean, there was a negative relationship between perceived 
effect on others and willingness to express opinions, simple slope $b=-0.10, S E=0.10, t=-1.00, p=.32$. The negative relationship between perceived effect on others and willingness to express opinions became stronger when perceived effect on self was at $2 \mathrm{SD}$ above its mean, simple slope $b=-0.20, S E=0.12, t=-1.67, p=.10$.

\section{Study 2 Introduction}

In study 1 , the volume of user ratings did not have a significant effect on perceived effect of user ratings and willingness to express opinion. A possibility is that ' 350 voters' may not have been sufficiently large enough to represent a high volume and the effect of volume needs to be further examined by adding more high volume conditions. Additionally, the effects of volume and valence on the third person effect could be examined by assessing the extent to which individuals change their self ratings and their estimated others' ratings before and after exposure to the user ratings. It is possible that as much as individuals perceive greater effect of user ratings on others than on self, they may also estimate that other people's ratings would change before and after exposure to the user ratings to a greater extent than their own ratings would. In sum, study 2 examined the effects of four different volume sizes and two valence types of user ratings on perceived effects of user ratings on self and others, self rating change and other rating change before and after exposure to user ratings, and willingness to express opinions.

\section{Study 2 Method}

\subsection{Participants and Design}

Two hundreds sixty six undergraduates (age $M=20.90 ; 64.2 \%$ women) in Communication and Advertising classes at Michigan State University and at University of Hawaii in the United States participated in the survey in exchange for extra credit. Similar to study 1 , Korean students were excluded from the analyses. The ethnic make-up of the participants were $70.1 \%$ Whites/Caucasian, 2.2\% Hispanic/Latino, 5.8\% Blacks/African Americans, $13.1 \%$ Asians, $2.2 \%$ other races, and $6.6 \%$ mixed (i.e. two or more races). For comparing the current sample with the U.S. population, see the study 1 method section of this paper which provides the U.S. Census demographic information of the U.S. population.

The current study used a 4 (volume: low, high, super high, and mega high) $\times 2$ (valence: positive and negative) $\times$ 2 (before and after exposure to user ratings) mixed design with volume and valence as between-subject factors. The volume of user ratings was manipulated through low (15 voters), high (350 voters), super high (1050 voters), and mega high (3150 voters) volume conditions. The valence of user rating was manipulated in the same way as in study 1 (i.e., negative valence $=$ one yellow-colored star; positive valence $=$ four yellow-colored stars). Participants were asked to indicate their self rating of a movie and their estimated ratings of other students before seeing the user ratings. After seeing the user ratings, participants indicated their self ratings of the movie and their estimated ratings of others again and responded to the items measuring perceived effects of user ratings and willingness to express opinions.

\subsection{Stimulus and Measurement}

Study 2 used only one movie, Secret Sunshine (a drama), as a stimulus material, unlike study 1 which used three movies (a comedy, a drama, and a horror film). A larger font size and different colors indicating volume (e.g. 1050 voters) were used to make the volume of user ratings more noticeable. The measurements (perceived effects of user ratings on self and others, and willingness to express opinions) and procedure of study 2 were the same as in study 1 . Table 4 reports reliabilities, means, standard deviations, and correlations of all variables.

In study 2, the effects of user ratings on self and others were operationalized in two ways: 1) the perceived effect of user ratings on self and others after exposure to the user ratings (TPE 1 - perceived effect of user ratings) and 2) participants' self rating change and estimated others' rating change before and after exposure to the user ratings (TPE 2 - rating change). The measurement for TPE 1 was the same as in study 1 . To measure the observed effect of user ratings on self and others (TPE 2), participants were asked to indicate their ratings of the movie and their estimated ratings of other students of the movie before and after being exposed to the manipulated user ratings. Each person's rating of the movie was measured with six items (interesting, boring [recoded], appealing, impressive, exciting, and like a waste of time [recoded]) and one additional item ("If you were to rate this movie, your rating of this movie would be out of 5" for self-rating; "If other students were to rate this movie, their rating of this movie would be out of 5 " for other-rating). The rating change was calculated by taking the absolute values of the difference between self ratings before and after exposure to user ratings (i.e., self rating change) and the difference between participants' estimated other ratings before and after exposure to user ratings (i.e., other rating change). 


\section{Study 2 Results}

The analyses here focused on the effects of the four volume conditions on TPE 1 (perceived effects of user ratings) and TPE 2 (rating change). The multiple regression analysis with willingness to express opinion as the dependent variable was not reported here because the results were highly similar to those already reported in study 1 . Table 5 reports means and standard deviations of the TPE 1, TPE 2 , and willingness to express opinions in each experimental condition.

\subsection{Perceived Effect of User Ratings on Self and Others}

\subsubsection{Target (H1)}

In analysis 1 (TPE 1 - perceived effect of user ratings), a 4 (volume: low, high, super high, and mega high) $\times 2$ (valence: positive and negative) $\times 2$ (target: self and others) mixed ANOVA was conducted to compare the perceived effect of user ratings on target (self and others). The analysis revealed a significant main effect for target, $F(1,254)=72.88, p<.001, \eta^{2}=.05$. The perceived effect of user rating on others $(M=2.65, S D=1.34)$ was significantly higher than on self $(M=2.01, S D=1.38)$.

In analysis 2 (TPE 2 - rating change), a 4 (volume: low, high, super high, and mega high) $\times 2$ (valence 1 : positive and negative) $\times 2$ (target: self and others) mixed ANOVA was conducted to compare self rating change and other rating change before and after exposure to user ratings. The analysis revealed a significant main effect for target, $F(1,257)=49.75, p<.001, \eta^{2}=.07$. Other rating change before and after exposure to user ratings $(M$ $=0.87, S D=0.89)$ was significantly greater than self rating change $(M=0.44, S D=0.42)$. Thus, the data were consistent with $\mathrm{H} 1$ which predicted that individuals would perceive user ratings to have greater effect on others than on self.

\subsubsection{Volume (H2) and valence}

With TPE 1 (perceived effect of user ratings) as the dependent variable, the analysis did not reveal significant main effects for volume, $F(3,254)=2.25, p=.08, \eta^{2}=.02$, or for valence, $F(1,254)=0.01, p=.92, \eta^{2}=.00$. Volume and valence did not interact significantly, $F(3,254)=0.06, p=.98, \eta^{2}=.00$. Volume did not interact with target, $F(1,254)=0.81, p=.49, \eta^{2}=.00$, and valence did not interact with target, $F(1,254)=0.40, p$ $=.53, \eta^{2}=.00$. The three-way interaction among volume, valence, and target was not significant, $F(1,254)=$ $1.20, p=.31, \eta^{2}=.001$.

With TPE 2 (rating change), the analysis did not reveal significant main effects for volume, $F(3,257)=1.35, p$ $=.26, \eta^{2}=.008$, or for valence, $F(1,257)=1.52, p=.22, \eta^{2}=.003$. Volume and valence did not interact significantly, $F(3,257)=0.43, p=.73, \eta^{2}=.00$. Volume did not interact with target, $F(1,257)=0.82, p=.49$, $\eta^{2}=.00$. The three-way interaction among volume, valence, and target was not significant, $F(1,257)=0.35, p$ $=.79, \eta^{2}=.00$. Thus, the data were inconsistent with $\mathrm{H} 2$ which predicted that the differential effects of user ratings on self and others would be greater in high volume than low volume conditions.

The two-way interaction between valence and target was significant, $F(1,257)=7.20, p=.008, \eta^{2}=.01$. The extent to which other rating change was larger than self rating change was greater in the positive valence condition (other rating change $M=0.98, S D=0.98$ versus self rating change $M=0.41, S D=0.38, t[148]=6.91$, $p<.001, \eta^{2}=.24$ ) than in the negative valence condition (other rating change $M=0.73, S D=0.74$ versus self rating change $\left.M=0.48, S D=0.47, t[115]=3.50, p=.001, \eta^{2}=.10\right)$.

\subsection{Willingness to Express One's Opinions}

To further examine the effect of volume, a 4 (volume: low, high, super high, and mega high) $\times 2$ (valence: positive and negative) between-subject ANOVA was conducted on willingness to express opinions. The results showed no main effect for volume, $F(3,257)=0.53, p=.66, \eta^{2}=.00$, no main effect for valence, $F(3,257)=$ $0.19, p=.66, \eta^{2}=.00$, and no interaction effect for volume and valence, $F(3,257)=0.59, p=.62, \eta^{2}=.00$.

\section{Discussion}

The purpose of this study was to explore the formation process of online user ratings of movies by focusing on the relationship between individuals' perceptions of online user ratings and willingness to express their opinions. In order to test the TPE of online user ratings and its role as a predictor of willingness to participate in user ratings, an online experiment with manipulated user ratings was conducted. The results indicated that people perceived the user ratings to have greater effects on others than on themselves. Moreover, people indicated that other rating changes would be larger than their own rating changes before and after exposure to user ratings. The volume and valence of user ratings did not affect the self-other gap of perceived effects and the gap of self and other rating changes. 
The Spiral of Silence theory argues that people who perceived their opinion to be in the minority may be less willing to express their opinion due to fear of isolation from others (Noelle-Neumann, 1974); however, the current study assumed that there may be a difference between peoples' willingness to express their opinions in off-line situations and online situations. On the Internet, people may have less fear of isolation than in off line conversations due to the main characteristic of the virtual world, anonymity. At this point, the current study questioned what the motivation could be for people to have more or less willingness to express their opinions on the Internet. Based on TPE reasoning, the findings showed that people's concern for the perceived effect of user ratings on others was a significant predictor of their willingness to express their opinions. Furthermore, the positive relationship between perceived effect of user ratings on others and willingness to express opinions was getting stronger as individuals minimized the perceived effect of user ratings on themselves.

An interesting finding was that, only in the negative valence condition, the valence discrepancy between user ratings and individuals' self ratings positively predicted willingness to express their opinions. As the gap grew between user ratings and self ratings, individuals in the negative valence condition were more willing to express their opinions, while those in the positive valence condition were less willing to express their opinions. A possibility for this finding might be that, in the negative valence condition (i.e., only one star out of five stars were yellow-colored), the increasing gap between the user ratings and self-ratings indicated individuals' more positive evaluation of the movies. Individuals with stronger positive evaluations of the movies might have been more motivated to express their opinions in order to influence others to be more positive about the movies. On the other hand, in the positive valence condition (i.e., four stars out of five stars were yellow-colored), the increasing gap between the user ratings and self-ratings indicated individuals' less positive evaluations of the movies. The more negative individuals were about the movies, the less concerned and the more disinterested they might have been about the movies and about what others would think. These are speculations that need to be further examined in future studies.

While the Spiral of Silence theory explains why people choose to be silent based on their perception of the opinion climate, the current study explained why people choose to speak out due to the interaction between individuals' own opinions and their perception of opinion climate. As the current study showed, concern for others who may be vulnerable to the poll results act as a significant motivation of individuals' willingness to participate in online polls. In addition, individuals' willingness would be influenced by their perception of public opinion climate. These results may provide more specific speculations about when people have more or less willingness to express their opinions That is, when opinion polls show negative opinion climate, individuals who have positive opinions may be more willing to express opinions; however, when opinion polls show positive opinion climates, individuals who have negative opinions may be more likely to avoid expressing their opinions.

Concerning volume of user ratings, the current study showing no significant effect of volume may appear inconsistent with the previous research findings, but the current study differed from the previous studies in a couple of aspects. Previous research used real user ratings about released movies on real Internet sites from times before to after their releases (Dellarocas et al., 2004; Duan et al., 2005; Liu, 2006), while this study used manipulated user ratings about unreleased movies. Thus, the volume of real user ratings which were used in previous research included both people's expectations about movies before their release and their evaluations of movies after their release, while the volume of user rating in the current study involved only people's expectations about unreleased movies. In addition, previous research might have been able to find significant effects of user rating volume on box office revenue because the number of participants of real user ratings could be related to the number of audience members who actually purchased movie tickets and watched the movies. Thus, the volume of real user ratings could be both an independent variable as well as a dependent variable, and that may explain why there might be a strong positive relationship between the volume of user ratings and box office revenues of movies; however, the volume of hypothetical user ratings of the current study was used only as an independent variable to affect people's perceptions of user rating results by showing the number of participants in hypothetical user ratings.

The results of studies 1 and 2 did not reveal a substantial or significant effect of volume of user ratings. It may suggest that people do not pay attention to the volume of public opinion polls when they view the results of public opinion polls. In relation to this phenomenon, Tversky and Kahneman (1974) explained that people use some heuristic principles when they have to judge uncertain events and probabilities. Intuitive judgments based on heuristic principles often neglect sample size and do not extract enough information from base rate information (Griffin and Tversky2002). That is, the current finding may indicate that people are more prone to believe the simple results of online opinion polls, regardless of sample size and whether or not it provides a valid general public opinion based on a large and representative sample. 


\subsection{Limitations}

A limitation of the current study involves the stimulus materials: Korean movies. The participants of study 1 indicated little interest in foreign movies $(M=2.80, S D=1.56$ on a 7-point scale with $1=$ not at all and $7=$ very much) or in Asian movies $(M=2.22, S D=1.29)$. Only $29.2 \%$ of the participants had the experience of watching Asian movies. Thus, the low willingness to participate in the user rating about an Asian movie may be due to their low interest in Asian movies regardless of their perception of user rating results. The roles of issue importance, personal involvement, and issue interest need to be investigated as moderators in further research.

Another limitation may pertain to how willingness to express opinions was measured. The current study asked participants to rate a movie, in order to be able to calculate the valence discrepancy, and then measured participants' willingness to participate in user ratings about the movie in imagined online situations. In a sense, one may argue that, because of the research design, participants had already participated in user ratings, regardless of their willingness. Thus, they may have perceived the questions that asked about their willingness to be redundant.

\section{Conclusion}

This study addressed an aspect of online user ratings by focusing on people's perceptions of others and the effects of user ratings on willingness to participate in user rating itself. Although the current study used movies as the stimulus materials for assessing people's willingness to express their opinions online, the findings may have implications beyond movies. When certain social issues start attracting people's attention on the Internet, individuals' perception of the online opinion climate can affect their decision to participate in online discussion of the social issues. If people with positive opinions differ from people with negative opinions in terms of how they participate in online discussion, such different participation pattern can have an impact on how online opinion climate may change over time. Further research in this area is needed to investigate how people perceive online communication and why people are more or less willing to participate in them. For example, a future research project may examine the effect of issue involvement on people's willingness to participate in online discussion especially after seeing online opinion climate to be in an opposite direction from their own opinions. Additionally, it would be interesting to examine various forms and types that individuals employ when expressing opinions because it is possible that some people may use explicit verbal messages while others may use implicit strategies. In sum, with increases in the importance of the Internet and the number of Internet users in areas such as exchange of information concerning various commercial products and services, educational matters, politics, just to name a few, it is beneficial to better understand the mechanism of individuals' and public opinion expression on the Internet.

\section{References}

Anderson, E. W. (1998). Customer satisfaction and word of mouth. Journal of Service Research, 1(1), 5-17.

Arndt, J. (1967). Word of mouth advertising and informal communication. In D. F. Cox (Ed.), Risk Taking and Information Handling in Consumer Behavior (pp. 188-239). Boston: Harvard University.

Davison, W. P. (1983). The third-person effect in communication. The Public Opinion Quarterly, 47(1), 1-15.

Dellarocas, C. N., Awad, N., \& Zhang, X. (2004). Using online ratings as a proxy of word-of mouth in motion picture revenue forecasting. Working paper, MIT Sloan School of Management. [Online] Available: http://ssrn.com/abstract=620821

Dichter, E. (1966). How word-of mouth advertising works. Harvard Business Reviews, 44(Nov-Dec), $147-166$.

Duan, W., Gu, B, \& Whinston, A. (2005). Do online reviews matter? An empirical investigation of panel data. Working paper, Department of Management Science and Information System, University of Texas at Austin.

Franklin, B. (1994). Packaging politics, London: Edward Arnold.

Griffin, D., \& Tversky, A. (2002). The weighing of evidence and the determinants of confidence. In T. Gilovich, D. Griffin, \& D. Kahneman (Eds.), Heuristics and biases: The psychology of intuitive judgment (pp. 230-249). New York: Cambridge University Press.

Gunther, A. C. (1995). Overrating the X-rating: The third-person perception and support for censorship of pornography. Journal of Communication, 45(1), 27-38.

Gunther, A. C., \& Storey, J. D. (2003). The influence of presumed influence. Journal of Communication, 53(2), $199-215$.

Kent, M. L., Harrison, T. R., \& Taylor, M. (2006). A critique of internet polls as symbolic representation and 
pseudo-event. Communication Studies, 57(3), 299-315.

Liu, Y. (2006). Word of mouth for movies: Its dynamics and impact on box office revenue. Journal of Marketing, 70(3), 74-89.

Morwitz, V. G., \& Pluzinski, C. (1996). Do polls reflect opinions or do opinions reflect polls? The impact of political polling on voters' expectations, preferences, and behaviors. The Journal of Consumer Research, 23(1), 53-67.

Noelle-Neumann, E. (1974). The spiral of silence: A theory of public opinion. Journal of Communication, 24(2), 43-51.

Ozcan, K. (2004). Consumer-to-consumer interactions in a networked society: word of mouth theory, consumer experiences, and network dynamics (Doctoral Dissertation, University of Michigan), Dissertation Abstracts International, 65(02), 611A. (UMI No. 765353291)

Perloff, R. M. (1999). The third-person effect: A critical review and synthesis. Media Psychology, 1(4), 353-378.

Rafaeli, S. (1988). Interactivity: From new media to communication. In R. P. Hawkin, J. M. Wiemann \& S. Pingree (Eds.), Advancing communication science: Merging Mass and interpersonal process (pp. 110-134). Newbury Park, CA: Sage.

Salwen, M. B., \& Driscoll, P. D. (1997). Consequences of third-person perception in support of press restrictions in the O. J. Simpson trial. Journal of Communication, 47, 60-75

Savigny, H. (2002). Public opinion, political communication and the internet. Politics, 22(1), 1-8.

Schultz, T. (1999). Interactive options in online journalism: a content analysis of 100 U.S. newspapers. Journal of Computer-Mediated Communication, 5, [Online] Available: http://jcmc.indiana.edu/vol5/issue1/schultz.html (December 10, 2007)

Schultz, T. (2000). Mass media and the concept of interactivity: an exploratory study of online forums and reader email. Media, Culture \& Society, 22(2), 205-221.

Shah, D., Faber, R. J., \& Youn, S. (1999). Susceptibility and severity: Perceptual dimensions underlying the third-person effect. Communication Research, 26(2), 240-267.

Tversky, A., \& Kahneman, D. (1974). Judgment under uncertainty: Heuristics and biases. Science, New Series, 185(4157), 1124-1131.

U.S. Census Bureau. (2000a). Age: 2000 (Brief No. C2KBR/01-12). [Online] Available: http://www.census.gov/prod/2001pubs/c2kbr01-12.pdf

U.S. Census Bureau. (2000b). Gender: 2000 (Brief No. C2KBR/01-9). [Online] Available: http://www.census.gov/prod/2001pubs/c2kbr01-9.pdf

U.S. Census Bureau. (2000c). Overview of race and Hispanic origin (Brief No. C2KBR/01-1). [Online] Available: http://www.census.gov/prod/2001pubs/c2kbr01-1.pdf

Wu, W., \& Weaver, D. (1997). On-line democracy or on-line demagoguery?: Public opinion "polls" on the internet. The Harvard International Journal of Press/Politics, 2(2), 71-86.

Table 1. Means and Standard Deviations of Study 1-Experimental Conditions

\begin{tabular}{|l|l|l|l|l|}
\hline & \multicolumn{2}{|l|}{ Low Volume } & \multicolumn{2}{l|}{ High Volume } \\
\hline & $\begin{array}{l}\text { Negative } \\
\text { Valence }\end{array}$ & $\begin{array}{l}\text { Positive } \\
\text { Valence }\end{array}$ & $\begin{array}{l}\text { Negative } \\
\text { Valence }\end{array}$ & $\begin{array}{l}\text { Positive } \\
\text { Valence }\end{array}$ \\
\hline Perceived effect on self & $2.19(1.44)$ & $1.97(0.28)$ & $2.00(1.40)$ & $1.69(1.19)$ \\
\hline Perceived effect on others & $2.71(1.29)$ & $2.67(0.17)$ & $2.71(1.37)$ & $2.59(1.13)$ \\
\hline total $^{\#}$ & $2.45(1.19)$ & $2.32(0.12)$ & $2.36(1.28)$ & $2.14(1.05)$ \\
\hline Willingness to express opinions & $1.75(1.02)$ & $1.67(0.98)$ & $1.59(1.04)$ & $1.50(0.88)$ \\
\hline & $\mathrm{n}=104$ & $\mathrm{n}=95$ & $\mathrm{n}=101$ & $\mathrm{n}=84$ \\
\hline
\end{tabular}

Standard deviations are reported in parentheses.

\# Total figures indicate an average of perceived effects on self and on others. 
Table 2. Questionnaire Items

\begin{tabular}{|c|c|}
\hline Variables & Measurement Items \\
\hline \multirow[t]{8}{*}{ Valence discrepancy } & To me, this movie seems to be....... \\
\hline & 1. Interesting \\
\hline & 2. Boring (reverse-coded) \\
\hline & 3. Appealing \\
\hline & 4. Impressive \\
\hline & 5. Exciting \\
\hline & 6. Like a waste of time (reverse-coded \\
\hline & $\begin{array}{l}\text { 7. If you were to rate this movie, your rating of this movie would } \\
\text { be out of } 5 \text {. }\end{array}$ \\
\hline \multirow[t]{3}{*}{$\begin{array}{l}\text { Perceived effect of user } \\
\text { ratings on self }\end{array}$} & $\begin{array}{l}\text { 1. How much do you think this rating has affected your rating of } \\
\text { this movie? }\end{array}$ \\
\hline & $\begin{array}{l}\text { 2. How much do you think this rating has affected your attitude } \\
\text { about this movie? }\end{array}$ \\
\hline & $\begin{array}{l}\text { 3. How much do you think this rating has affected your } \\
\text { expectations of this movie? }\end{array}$ \\
\hline \multirow[t]{3}{*}{$\begin{array}{l}\text { Perceived effect of user } \\
\text { ratings on other students }\end{array}$} & $\begin{array}{l}\text { 1. How much do you think this rating has affected other students' } \\
\text { ratings of this movie? }\end{array}$ \\
\hline & $\begin{array}{l}\text { 2. How much do you think this rating has affected other students' } \\
\text { attitudes about this movie? }\end{array}$ \\
\hline & $\begin{array}{l}\text { 3. How much do you think this rating has affected other students' } \\
\text { expectations of this movie? }\end{array}$ \\
\hline \multirow[t]{3}{*}{$\begin{array}{l}\text { Willingness to express one's } \\
\text { opinion }\end{array}$} & $\begin{array}{l}\text { 1. If you were to see information about this move on other } \\
\text { website, how much would you wish to participate in a user } \\
\text { rating of this movie? }\end{array}$ \\
\hline & $\begin{array}{l}\text { 2. If you were to see information about this move on other } \\
\text { website, how much would you wish to write a user review of } \\
\text { this movie? }\end{array}$ \\
\hline & $\begin{array}{l}\text { 3. If your class were to deal with this movie as a discussion topic, } \\
\text { how much would you wish to participate in the class } \\
\text { discussion? }\end{array}$ \\
\hline
\end{tabular}

Response option for each question was

$\begin{array}{lllllll}\text { "Not at all } & 0 & 1 & 2 & 3 & 4 & 5 \text { Very much" }\end{array}$ 
Table 3. Regression results for Willingness to Express Opinions

\begin{tabular}{|c|c|c|c|c|c|}
\hline & $B$ & $S E$ & $\beta$ & $t$ & $s r$ \\
\hline \multicolumn{6}{|l|}{ First Block } \\
\hline Volume $^{1}$ & 0.12 & 0.10 & .06 & 1.21 & .06 \\
\hline Valence $^{2}$ & 0.02 & 0.12 & .01 & 0.18 & .01 \\
\hline Valence Discrepancy $^{3}$ & 0.04 & 0.05 & .05 & 0.81 & .04 \\
\hline Perceived Effect on Self & 0.07 & 0.05 & .10 & 1.49 & .07 \\
\hline Perceived Effect on Others & 0.12 & 0.05 & .15 & $2.36^{*}$ & .12 \\
\hline \multicolumn{6}{|c|}{$F(5,380)=4.77, p<.001$, adj. $R^{2}=.05$} \\
\hline \multicolumn{6}{|l|}{ Second Block } \\
\hline Volume $\times$ Valence & -0.23 & 0.23 & -.10 & -0.98 & -.05 \\
\hline Volume $\times$ Discrepancy & -0.16 & 0.11 & -.13 & -1.56 & -.08 \\
\hline Volume $\times$ Perceived Effect on Self & 0.03 & 0.09 & .03 & 0.34 & .02 \\
\hline Volume $\times$ Perceived Effect on Others & 0.15 & 0.10 & .14 & 1.52 & .07 \\
\hline Valence $\times$ Valence Discrepancy & -0.48 & 0.12 & -.30 & $-4.15^{* * *}$ & -.20 \\
\hline Valence $\times$ Perceived Effect on Self & 0.09 & 0.11 & .07 & 0.80 & .04 \\
\hline Valence $\times$ Perceived Effect on Others & -0.06 & 0.12 & -.04 & -0.48 & -.02 \\
\hline $\begin{array}{l}\text { Valence Discrepancy } \times \text { Perceived Effect } \\
\text { on Self }\end{array}$ & -0.01 & 0.04 & -.01 & -0.18 & -.01 \\
\hline $\begin{array}{l}\text { Valence Discrepancy } \times \text { Perceived Effect } \\
\text { on Others }\end{array}$ & 0.03 & 0.05 & .05 & 0.75 & .04 \\
\hline $\begin{array}{l}\text { Perceived Effect on Self } \times \text { Perceived } \\
\text { Effect on Others }\end{array}$ & -0.08 & 0.03 & -.14 & $-2.76^{* *}$ & -.13 \\
\hline$F_{\text {change }}(10,370)=3$ & . & $\kappa$ & $\mathrm{e}=.08$ & & \\
\hline
\end{tabular}

$* p<.05, * * p<.01, * * * p<.001$

$s r$ : semipartial correlation

The first-order and second-order predictors had variance inflation factors (VIF) ranging from 1.01 to 5.49, indicating no serious threat concerning multicollinearity.

${ }^{1}$ dummy-coded with low volume $=0$ and high volume $=1$

${ }^{2}$ dummy-coded with negative valence $=0$ and positive valence $=1$

${ }^{3}$ Valence Discrepancy was calculated as the absolute difference between the user ratings and participants' self rating before being exposed to the user ratings. 
Table 4. Reliabilities, Means, Standard Deviations and Correlations of Variables of Study 2

\begin{tabular}{|c|c|c|c|c|c|c|c|}
\hline Study 2 & 1 & 2 & 3 & 4 & 5 & 6 & 7 \\
\hline $\begin{array}{l}\text { 1. Self Rating } \\
\text { before Exposure }\end{array}$ & .90 & & & & & & \\
\hline $\begin{array}{l}\text { 2. Others' Rating } \\
\text { before Exposure }\end{array}$ & $.57 * *$ & .88 & & & & & \\
\hline $\begin{array}{l}\text { 3. Self Rating } \\
\text { after Exposure }\end{array}$ & $.84 * *$ & $.51 * *$ & .91 & & & & \\
\hline $\begin{array}{l}\text { 4. Others' Rating } \\
\text { after Exposure }\end{array}$ & $.28 * *$ & $.44^{* *}$ & $.44 * *$ & .93 & & & \\
\hline 5. Perceived Effect on Self & $.29 * *$ & .01 & $.31 * *$ & .06 & .90 & & \\
\hline 6. Perceived Effect on Other & $.19^{*}$ & .11 & $.21^{*}$ & $.22 * *$ & $.62 * *$ & .96 & \\
\hline 7. Willingness to Express Opinion & $.35 * *$ & $.22 * *$ & $.36^{* *}$ & $.17^{*}$ & $.30 * *$ & $.26^{* *}$ & .75 \\
\hline total & $\begin{array}{l}2.22 \\
(1.06)\end{array}$ & $\begin{array}{l}2.02 \\
(0.93)\end{array}$ & $\begin{array}{l}2.12 \\
(1.04)\end{array}$ & $\begin{array}{l}2.27 \\
(1.18)\end{array}$ & $\begin{array}{l}1.90 \\
(1.42)\end{array}$ & $\begin{array}{l}2.50 \\
(1.41)\end{array}$ & $\begin{array}{l}1.77 \\
(1.10)\end{array}$ \\
\hline
\end{tabular}

${ }^{*} p<.05,{ }^{* *} p<.01, d f$ ranged from 140 to 142 .

Reliabilities (Cronbach's $\alpha$ ) are reported on the diagonal.

Table 5. Means and Standard Deviations of Study 2-Experimental Conditions

\begin{tabular}{|c|c|c|c|c|c|c|c|c|}
\hline & \multicolumn{2}{|c|}{ Low Volume } & \multicolumn{2}{|c|}{ High Volume } & \multicolumn{2}{|c|}{$\begin{array}{l}\text { Super High } \\
\text { Volume }\end{array}$} & \multicolumn{2}{|c|}{$\begin{array}{l}\text { Mega High } \\
\text { Volume }\end{array}$} \\
\hline & $\begin{array}{l}\text { Neg. } \\
\text { Val. }\end{array}$ & $\begin{array}{l}\text { Pos. } \\
\text { Val. }^{2}\end{array}$ & $\begin{array}{l}\text { Neg. } \\
\text { Val. }\end{array}$ & $\begin{array}{l}\text { Pos. } \\
\text { Val. }\end{array}$ & $\begin{array}{l}\text { Neg. } \\
\text { Val. }\end{array}$ & Pos. Val. & $\begin{array}{l}\text { Neg. } \\
\text { Val. }\end{array}$ & $\begin{array}{l}\text { Pos. } \\
\text { Val. }\end{array}$ \\
\hline Perceived effect on self & $\begin{array}{l}1.85 \\
(1.21)\end{array}$ & $\begin{array}{l}1.73 \\
(1.38)\end{array}$ & $\begin{array}{l}2.50 \\
(1.46)\end{array}$ & $\begin{array}{l}2.38 \\
(1.16)\end{array}$ & $\begin{array}{l}1.83 \\
(1.29)\end{array}$ & $\begin{array}{l}1.93 \\
(1.32)\end{array}$ & $\begin{array}{l}1.87 \\
(1.50)\end{array}$ & $\begin{array}{l}1.93 \\
(1.71)\end{array}$ \\
\hline Perceived effect on others & $\begin{array}{l}2.69 \\
(1.32)\end{array}$ & $\begin{array}{l}2.60 \\
(1.31)\end{array}$ & $\begin{array}{l}2.80 \\
(1.35)\end{array}$ & $\begin{array}{l}3.06 \\
(0.88)\end{array}$ & $\begin{array}{l}2.60 \\
(1.47)\end{array}$ & $\begin{array}{l}2.47 \\
(1.20)\end{array}$ & $\begin{array}{l}2.38 \\
(1.53)\end{array}$ & $\begin{array}{l}2.48 \\
(1.65)\end{array}$ \\
\hline $\operatorname{total}^{\#}$ & $\begin{array}{l}2.27 \\
(1.14)\end{array}$ & $\begin{array}{l}2.16 \\
(1.26)\end{array}$ & $\begin{array}{l}2.65 \\
(1.24)\end{array}$ & $\begin{array}{l}2.77 \\
(0.91)\end{array}$ & $\begin{array}{l}2.21 \\
(1.26)\end{array}$ & $\begin{array}{l}2.24 \\
(1.14)\end{array}$ & $\begin{array}{l}2.13 \\
(1.45)\end{array}$ & $\begin{array}{l}2.20 \\
(1.45)\end{array}$ \\
\hline $\begin{array}{l}\text { Self rating change before and } \\
\text { after exposure }\end{array}$ & $\begin{array}{l}0.47 \\
(0.45)\end{array}$ & $\begin{array}{l}0.44 \\
(0.40)\end{array}$ & $\begin{array}{l}0.56 \\
(0.37)\end{array}$ & $\begin{array}{l}0.44 \\
(0.41)\end{array}$ & $\begin{array}{l}0.49 \\
(0.51)\end{array}$ & $\begin{array}{l}0.38 \\
(0.36)\end{array}$ & $\begin{array}{l}0.43 \\
(0.55)\end{array}$ & $\begin{array}{l}0.41 \\
(0.36)\end{array}$ \\
\hline $\begin{array}{l}\text { Other rating change before } \\
\text { and after exposure }\end{array}$ & $\begin{array}{l}0.84 \\
(0.79)\end{array}$ & $\begin{array}{l}1.13 \\
(0.93)\end{array}$ & $\begin{array}{l}0.91 \\
(0.95)\end{array}$ & $\begin{array}{l}0.95 \\
(1.03)\end{array}$ & $\begin{array}{l}0.64 \\
(0.62)\end{array}$ & $\begin{array}{l}1.00 \\
(0.99)\end{array}$ & $\begin{array}{l}0.56 \\
(0.52)\end{array}$ & $\begin{array}{l}0.81 \\
(0.97)\end{array}$ \\
\hline total & $\begin{array}{l}0.66 \\
(0.48)\end{array}$ & $\begin{array}{l}0.79 \\
(0.52)\end{array}$ & $\begin{array}{l}0.74 \\
(0.56)\end{array}$ & $\begin{array}{l}0.69 \\
(0.62)\end{array}$ & $\begin{array}{l}0.56 \\
(0.47)\end{array}$ & $\begin{array}{l}0.69 \\
(0.51)\end{array}$ & $\begin{array}{l}0.49 \\
(0.45)\end{array}$ & $\begin{array}{l}0.61 \\
(0.56)\end{array}$ \\
\hline $\begin{array}{l}\text { Willingness to express } \\
\text { opinions }\end{array}$ & $\begin{array}{l}1.57 \\
(1.18)\end{array}$ & $\begin{array}{l}1.59 \\
(1.03)\end{array}$ & $\begin{array}{l}1.88 \\
(1.00)\end{array}$ & $\begin{array}{l}1.74 \\
(1.05)\end{array}$ & $\begin{array}{l}1.76 \\
(1.16)\end{array}$ & $\begin{array}{l}1.74 \\
(1.11)\end{array}$ & $\begin{array}{l}1.61 \\
(1.12)\end{array}$ & $\begin{array}{l}1.98 \\
(0.99)\end{array}$ \\
\hline & $\mathrm{n}=25$ & $\mathrm{n}=28$ & $\mathrm{n}=30$ & $\mathrm{n}=37$ & $\mathrm{n}=32$ & $\mathrm{n}=56^{\# \#}$ & $\mathrm{n}=29$ & $\mathrm{n}=27$ \\
\hline
\end{tabular}

Standard deviations are reported in parentheses.

${ }^{1}$ Negative Valence

${ }^{2}$ Positive Valence

\# Total figures indicate an average of perceived effects on self and on others.

\#\# Accidentally, more participants were assigned to this condition than to other conditions. 